\title{
Investigation on Thermo-physical Properties of L- Valinium Picrate Single Crystal for Modern Applications
}

\author{
M Manivannan ( $\sim$ manimathi28@gmail.com ) \\ Pachamuthu College of arts and Science for women
}

\section{S. Balachandar}

Research and Development, AKSH Opticfibre

M. Jose

Department of Physics, Abdul Kalam Research Centre, Sacred Heart College

S A Martin Britto Dhas

Department of Physics, Abdul Kalam Research Centre, Sacred Heart College

\section{Research Article}

Keywords: L-valinium picrate, HRXRD, photoacoustic spectrometer, thermophysical properties, crystal growth

Posted Date: March 30th, 2021

DOl: https://doi.org/10.21203/rs.3.rs-358174/v1

License: (9) This work is licensed under a Creative Commons Attribution 4.0 International License. Read Full License 


\section{Abstract}

Good quality L-valinium picrate single crystal was grown by slow evaporation technique. The lattice parameters of the crystal were measured by single crystal X-ray diffraction analysis. The High resolution $\mathrm{X}$-ray diffraction study reveals good crystalline perfection of the grown crystals. The thermal diffusivity and specific heat capacity were experimentally measured using photoacoustic technique and standard DSC technique, respectively. The thermo physical properties such as thermal conductivity, thermal diffusivity, specific heat capacity, volumetric specific heat capacity, and thermal effusivity of LVP are reported for the first time at ambient temperature.

\section{Introduction}

For the last few decades the technologists and scientists have paying attention to both organic and inorganic nonlinear materials, due to their technological applications. Nonlinear optical (NLO) materials have fascinated more due to their enormous of applications such as frequency conversion, optical switching, optical memory storage, colour display, optical information processing, photonics and second harmonic generation (SHG) [1-2]. All the amino acids are attractive organic materials for NLO applications by possessing carboxylic donor and amino acceptor group but these applications are mainly depends upon the dissimilar properties of the materials, such as transparency, laser damage threshold, hardness, birefringence, dielectric constant, thermal properties and chemical stability [3].

Thermal transport properties like thermal diffusivity, thermal conductivity and thermal effusivity play a significant role in process involving heat transfer [4]. Among standard transient methods, laser flash method [5] and photothermal techniques are most popular methods for the estimation of thermal diffusivity of solids and to characterize/evaluate the thermal behaviours [6-8]. Particularly, in the field of applied optics, Photonics, crystals utilized for harmonic generation, light amplification, transmission, and manipulation, the understanding of the above thermal properties are decisive. The internal heat generation within the crystal produces a time varying temperature profile which significantly affects the quality of the output [9]. Therefore, the knowledge of thermal transport properties at ambient temperature is essential for selection of material, optimizing output beam quality, thermal management, efficient design of optical system etc. Recently, several nonlinear optical materials are identified for potential applications, but data for thermophysical properties are still lacking in the literature. The above said properties are mandatory for laser design using NLO materials; subjected to high power laser irradiation [9]. Photoacoustic spectroscopy (PAS) is one of the viable non-destructive techniques for estimation of the thermo physical properties of solids [10-11].

Moreover, thermo-physical properties of certain NLO materials such as L-alaninium maleate [12], Lthreonine and L-prolinum tartarate [13] were investigated using photoacoustic spectroscopic analysis and it reveals the potential applicability of photoacoustic spectroscopy as a probe to investigate the thermal properties of solids. In order to, replace the place of KDP, a large number of organic NLO materials were identified and reported in literature for harmonic generation. Among these, L-Valinium picrate is identified 
as one of the potential NLO materials due to its high efficiency of second harmonic generation (60 times higher than that of standard KDP crystal). Even though, growth, vibrational, linear and nonlinear optical properties were reported in the literature [14-15]. To the best of our knowledge, the thermal parameters of LVP are yet to be explored. This paper reports the thermophysical properties of L-valinium picrate single crystal.

\section{Experimental Section}

L-Valinium picrate $\left(\mathrm{C}_{5} \mathrm{H}_{12} \mathrm{NO}_{2}\right)^{+},\left(\mathrm{C}_{6} \mathrm{H}_{2} \mathrm{~N}_{3} \mathrm{O}_{7}\right)^{-}$was synthesised by dissolving equimolar ratio of L-Valine and picric acid in aqueous solution by constant stirring at ambient temperature. The saturated solution was filtered and covered by polyethylene sheet with a few holes and allowed for slow evaporation at ambient temperature in a dust and vibration free environment. After the growth period of two weeks a good quality bulk size LVP crystal has harvested. The grown crystals were found to be yellow in colour. The cut and polished as grown crystal of LVP with the diameter of $10 \mathrm{~mm}$ and thickness $1 \mathrm{~mm}$ is shown in Fig. 1.

In order to confirm the identity of grown crystal and to obtain the cell parameters, single crystal X-ray diffraction study was carried out by Nonius CAD-4/MACH 3 diffractometer, with MoKa radiation (0.71073 $\AA$ ). To reveal the crystalline perfection of the grown crystal, a multi-crystal X-ray diffractometer (MCD) developed at NPL [16] has been used to record high-resolution diffraction curves (DCs). In this system a fine focus $(0.4 \times 8 \mathrm{~mm} ; 2 \mathrm{~kW} \mathrm{Mo}) \mathrm{X}$-ray source energized by a well-stabilized Philips X-ray generator (PW 1743) was employed. A LVP crystal of (100) diffracting planes in symmetrical Bragg geometry was subjected to multi-crystal X-ray diffraction.

The thermal properties of LVP is analysed by a photoacoustic spectrometer which was constructed in our laboratory. The performance of the constructed photoacoustic spectrometer is calibrated with standard samples Viz., BK7 glass, quartz glass and KDP crystals with a dimension of $10 \times 10 \times 1 \mathrm{~mm}^{3}$. A well polished LVP crystal in (100) direction with dimensions $3 \times 3 \times 1 \mathrm{~mm}^{3}$ is placed in the sample cell and the sample surface is exposed to a collimated and modulated (by two blade mechanical chopper) beam of tungsten-filament light source. The distance from the sample to the detector is fixed as $1 \mathrm{~mm}$. The periodic heating in the sample generates PA signal. The generated Photoacoustic (PA) signal in the sample cell is detected by a sensitive microphone controlled by computer with sound recording software.

\section{Results And Discussion}

The grown crystals without any visible inclusions were selected and subjected for X-ray diffraction analysis. The unit cell parameters were obtained from the least-squares refinement of the setting angles of 25 reflections. The obtained lattice parameters are: $a=9.962$ (11) $\AA, b=6.271$ (5) $\AA, c=12.623$ (9) $\AA, \beta$ $=110.7(3)^{\circ}$ and it belongs to monoclinic system, these values is well agreement with the literature [17] and confirms that the grown crystal is LVP. The absorption and heat transport properties of material mainly depends on the crystalline perfection, the crystalline perfection is examined by Diffraction Curve 
(DC). The DC (Fig. 2) is quite sharp without any satellite peaks which may otherwise be observed due to internal structural grain boundaries [18-19]. The Full Width at Half Maximum (FWHM) of the diffraction curves is 18 arc sec, which is very close to the expected value from the plane wave dynamical theory of Xray diffraction [20]. The result shows that the crystalline perfection of the grown crystal is good and the crystal is suitable for the further measurements to get accurate results.

Thermal diffusivity estimation using PAS $[6,10]$ involves the study of phase and amplitude character of acoustic wave in closed volume for the given different chopping frequencies. The plot between normalized photoacoustic signal amplitude verses square root of chopping frequency is used to estimate critical chopping frequency. At critical chopping frequency thermal diffusion length is equal to sample thickness and thermal diffusivity is estimated from the given sample thickness and estimated critical frequency. The normalized spectrum of PA signal versus square root of chopping frequency for the KDP and LVP crystals are shown in Fig. 3. From this spectrum the thermal diffusivity was calculated by curve fitting method by adopting Barros Mela and Fariea [21] and the results are listed in Table 1. The obtained values for the KDP are in good agreement with the literature values [22]. The above said experiment was repeated for the LVP crystal and the thermal diffusivity was measured as $5.12 \times 10^{-6} \mathrm{~m}^{2} \mathrm{~s}^{-1}$. The thermal diffusivity of LVP crystal seems to be five times greater than that of KDP crystal and hence it can be evidenced that LVP crystal can sustain for high power laser applications.

Since specific heat capacity value is necessary to estimate the thermal conductivity from thermal diffusivity, differential scanning calorimetric (DSC) was carried out to measure the specific heat capacity of LVP and shown in Fig. 4. The specific heat capacity of LVP crystal at $30^{\circ} \mathrm{C}$ temperature is obtained as $344.01 \mathrm{Jkg}^{-1} \mathrm{k}^{-1}$ and the thermal properties are listed in Table 1.

Table I. Thermo physical properties of the standard sample and LVP crystal

\begin{tabular}{|c|c|c|c|c|c|c|}
\hline \multirow[t]{2}{*}{$\begin{array}{l}\text { Sample } \\
\text { Name }\end{array}$} & \multicolumn{2}{|c|}{$\begin{array}{l}\text { Thermal diffusivity } \\
10^{-6}\left(\mathrm{~m}^{2} / \mathrm{s}\right)\end{array}$} & \multicolumn{2}{|c|}{$\begin{array}{l}\text { Thermal Effusivity } \\
10^{3}\left(\mathrm{~m}^{-2} \mathrm{~K}^{-1} \mathrm{~S}^{-1 / 2}\right)\end{array}$} & \multicolumn{2}{|c|}{$\begin{array}{l}\text { Thermal Conductivity } \\
\left(\mathrm{Wm}^{-1} \mathrm{~K}^{-1}\right)\end{array}$} \\
\hline & $\begin{array}{l}\text { Experimental } \\
\text { value }\end{array}$ & $\begin{array}{l}\text { Literature } \\
\text { value }\end{array}$ & $\begin{array}{l}\text { Experimental } \\
\text { value }\end{array}$ & $\begin{array}{l}\text { Literature } \\
\text { value }\end{array}$ & $\begin{array}{l}\text { Experimental } \\
\text { Value }\end{array}$ & $\begin{array}{l}\text { Literature } \\
\text { value }\end{array}$ \\
\hline KDP & 0.9707 & 0.9500 & 1.9741 & 1.9529 & 1.9449 & 1.9049 \\
\hline LVP & $5.126(20)$ & - & 1.1985 & - & 2.71245 & - \\
\hline
\end{tabular}

\section{Conclusion}

Bulk size single crystal of LVP crystal was grown by slow evaporation technique at ambient temperature. The X-ray diffraction and HRXRD confirms the crystal structure and good crystalline nature of the grown crystal. Photoacoustic technique facilitates to measure thermal diffusivity of LVP and it exhibits that the value of thermal diffusivity of LVP is more than five times that of the value of thermal diffusivity of 
Potassium Di-hydrogen Phosphate (KDP) single crystal. The specific heat capacity is measured by Differential Scanning Calorimetric (DSC) technique. At ambient temperature $30^{\circ} \mathrm{C}$, the values of the thermal conductivity, thermal diffusivity, specific heat capacity, volumetric specific heat capacity and thermal effusivity were found and reported for the first time as $2.71245 \mathrm{Wm}^{-1} \mathrm{k}^{-1}, 5.12 \times 10^{-6} \mathrm{~m}^{2} \mathrm{~s}^{-1}$, $344.01 \mathrm{Jkg}^{-1} \mathrm{k}^{-1}, 529.7754 \times 10^{3} \mathrm{Jm}^{-3} \mathrm{k}^{-1}$ and $1.1985 \times 10^{3} \mathrm{Ws}^{1 / 2} \mathrm{k}^{-1} \mathrm{~m}^{-2}$ respectively.

\section{Declarations}

\section{Acknowledgement}

The authors acknowledge Prof. Madan Kumar, Department of English, Sacred Heart College for language correction. The authors acknowledge G. Bhagavannarayana, NPL, New Delhi, India for providing facility to measure the crystalline perfection.

\section{References}

1. Senthil K, Hamada F, Yamada M and Aravindan P.G, Opt. Mater. 46:565 (2015).

2. Hanumantharao R and Kalainathan S, J. Chem. 305932, 4 (2013).

3. Martin Britto Dhas S.A, Bhagavannarayana G and Natarajan S, Crystallogr. J, 1: 42 (2008).

4. Marin E. Eur J. Phys.28: 429 (2007).

5. Parker W J, Jenkins R J, Butler C P, Abbott G L, JAP, 32: 1679 (1961).

6. Mandelis A. Journal of Thermal Analysis 37: 1065 (1991).

7. Vargas H and Miranda L C M. Rev. of Sci. Instru. 74: 794 (2003).

8. Almond D P, and Patel P M Chapman and Hall, London, 1996

9. Zahra M, Maryam J, Samira A, Samira D, Shahram K, Optics \& Laser tech 44: 1095 (2012).

10. Rosencwaig A and Gersho A. J. Appl Phy. 47: 64 (1976).

11. Boccara A C, Fournier D, Badoz. Appl. Phys. Lett. 36: 130 (1980).

12. Martin Britto Dhas S.A, Raji P, Ramachandran K, Ramachandran E and Natarajan S, Cryt.Res.Technol.42: 601 (2007).

13. Martin Britto Dhas S. A, Suresh M, Raji P, Ramachandran K and Natarajan S, Cryt.Res.Technol. 42: 190 (2007).

14. Martin Britto Dhas S.A and Natarajan S, Cryst. Res. Technol. $42: 471$ (2008).

15. Senthilkumar S, Briget Mary M and Ramakrishna V, J. Raman Spectrosc. 38: 288 (2007).

16. Lal K and Bhagavannarayana G, J. Appl. Cryst. 22: 209 (1989).

17. Anitha K, Sridhar B, and Rajaram R.K, Acta Cryst. E 60: 01530 (2004).

18. Bhagavannarayana G, Ananthamurthy R.V, Budakoti G.C, Kumar B and Bartwal K.S, J. Appl. Cryst. 38:768 (2005). 
19. Bhagavannarayana G, Parthiban S and Meenakshisundaram S, J. Appl. Cryst. 39:784 (2006). 20. Betterman B.W and Cole H. Rev. Mod. Phys. 36: 681 (1964).

21. B Melo W. L and Faria R. M, Appl. Phys. Lett. 67:3892 (1995).

22. H Minemoto, Yusuke Ozaki, Nobuo Sonoda, and Takatomo Sasaki Appl. Phys. 76: 3975 (1994).

\section{Figures}

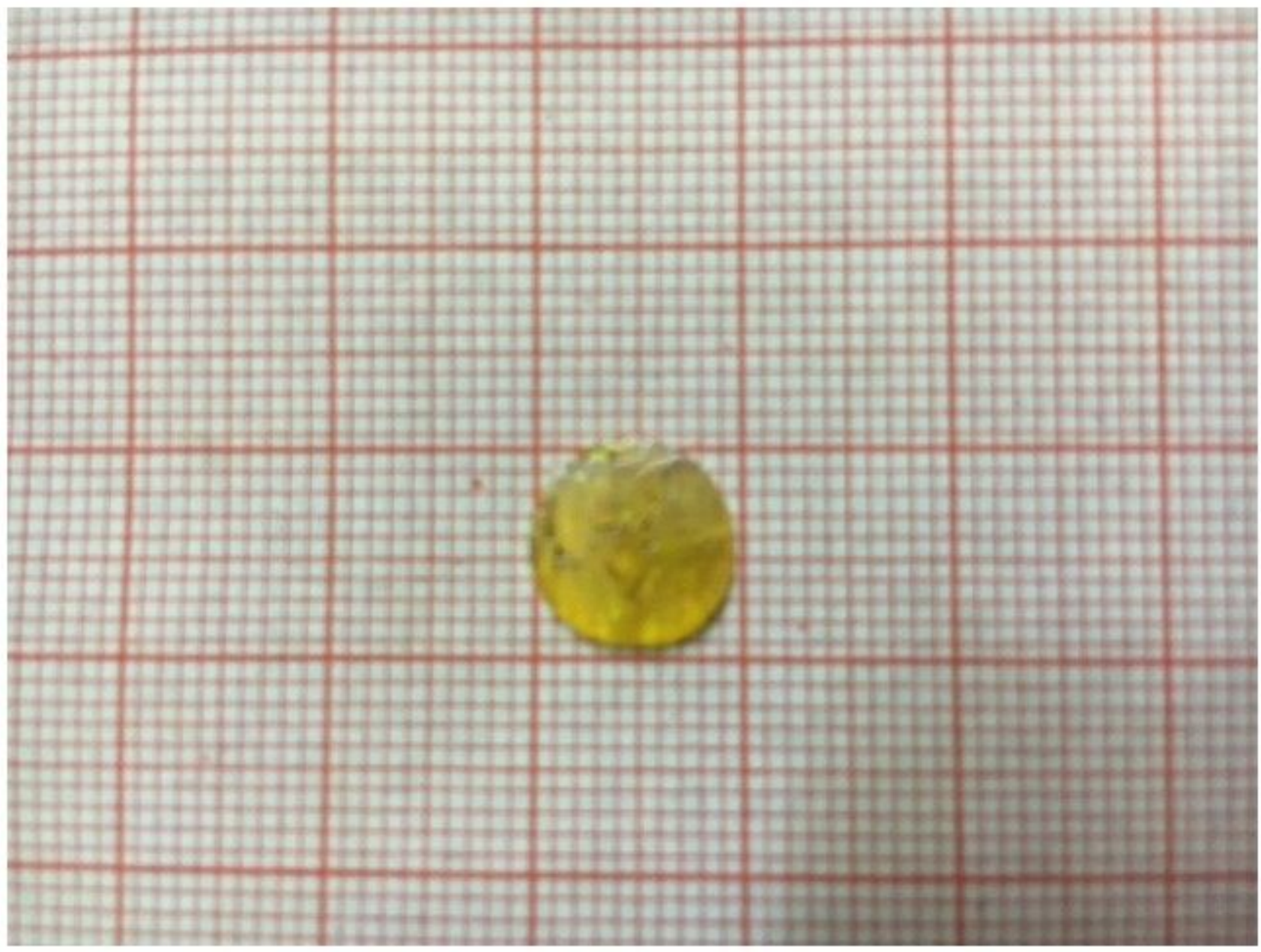

\section{Figure 1}

Photograph of cut and polished LVP crystal 


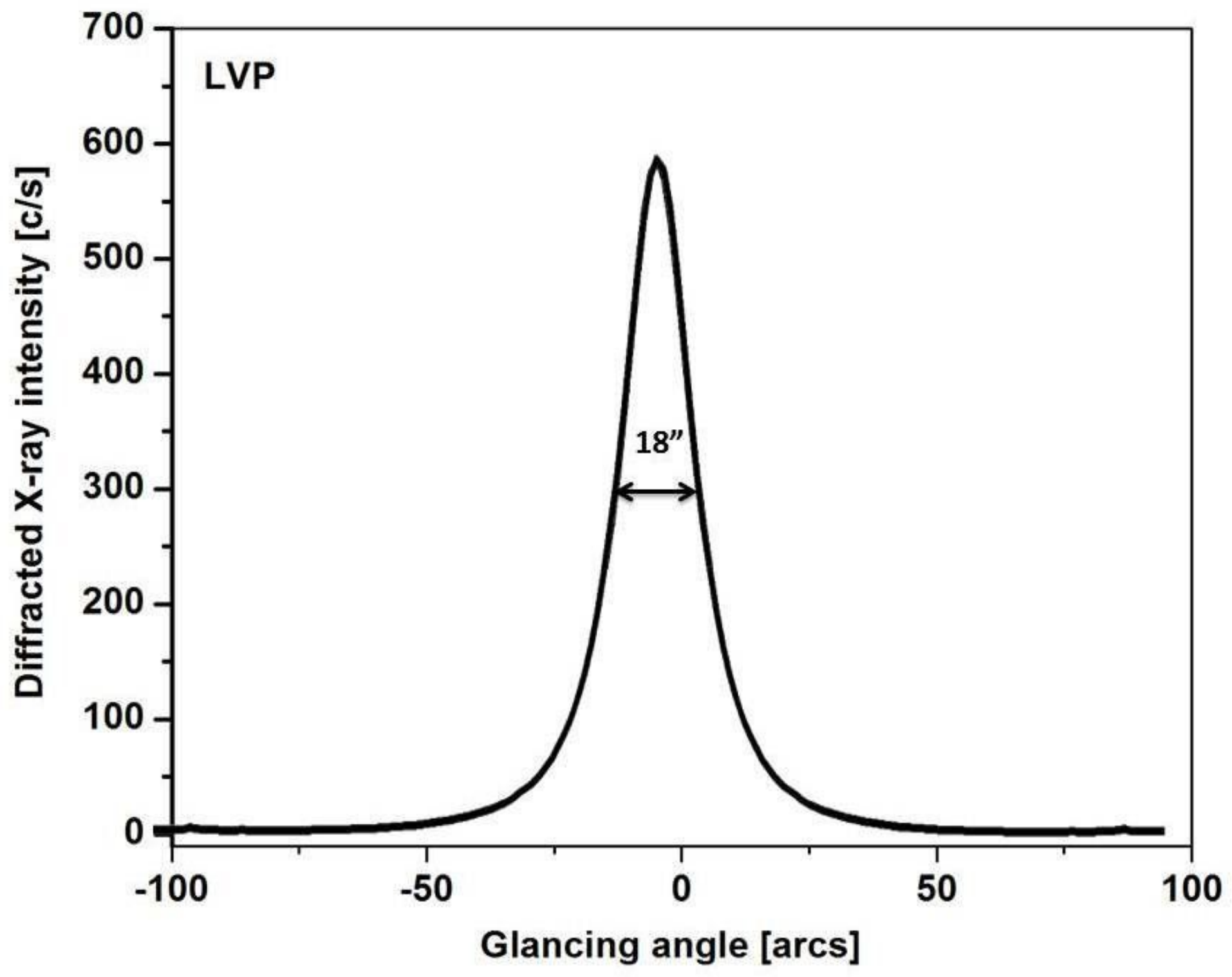

Figure 2

Diffraction curve recorded for LVP single crystal for (100) diffracting planes 


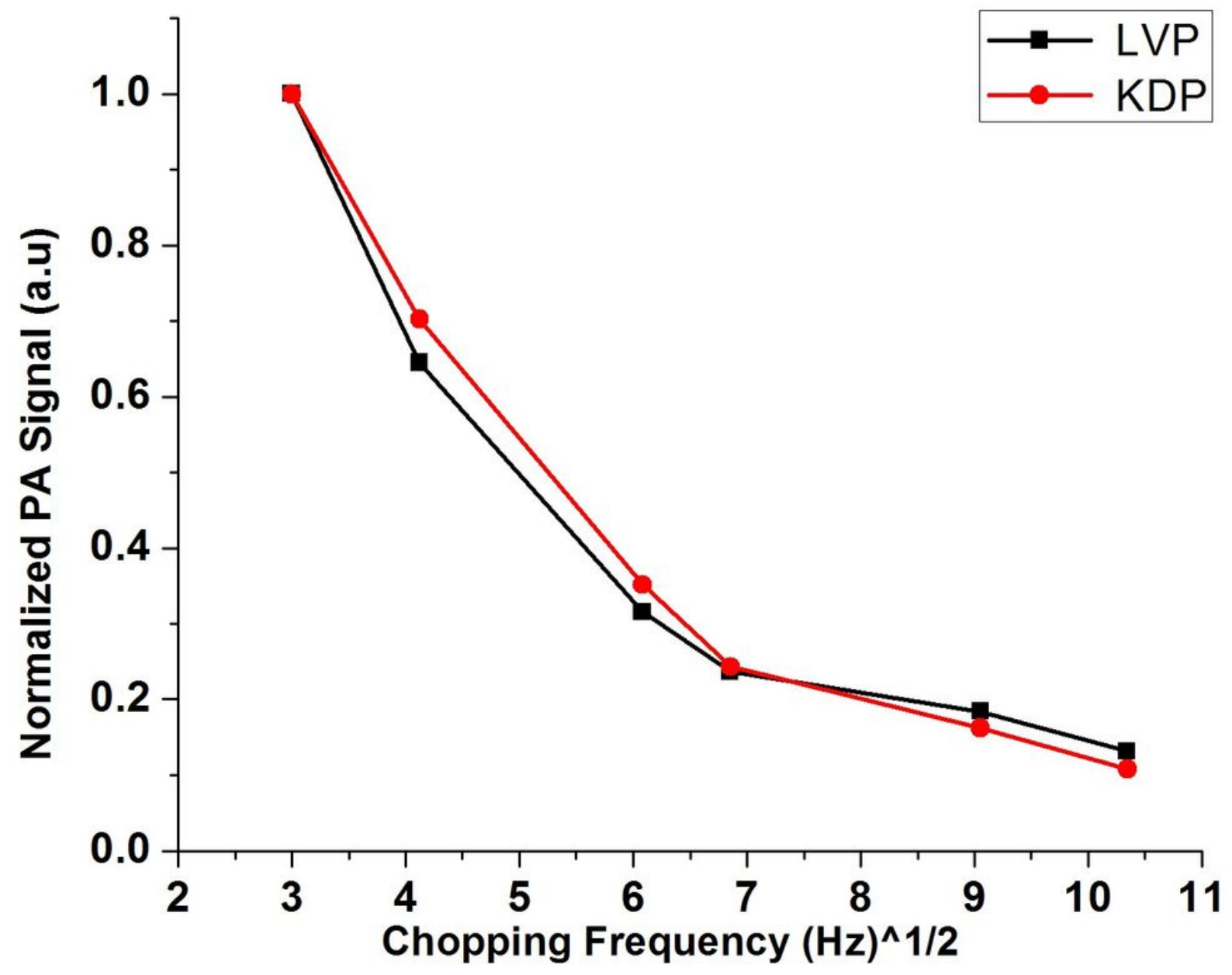

Figure 3

chopping frequency Vs normalized PA signal of KDP and LVP crystals 




Figure 4

DSC thermogram of LVP crystal 